\begin{tabular}{|c|c|c|}
\hline \multirow[t]{2}{*}{ BENTHAM OPEN } & $\begin{array}{c}\text { The Open Bioactive Compounds } \\
\text { Journal }\end{array}$ & $\begin{array}{l}\text { The Open } \\
\text { Bioactive Compounds } \\
\text { lournal }\end{array}$ \\
\hline & $\begin{array}{l}\text { Content list available at: www.benthamopen.com/TOBCJ/ } \\
\text { DOI: } 10.2174 / 1874847301705010057\end{array}$ & 200 \\
\hline
\end{tabular}

REVIEW ARTICLE

\title{
Insight into Erythrina Lectins: Properties, Structure and Proposed Physiological Significance
}

\author{
Makarim Elfadil M. Osman and Emadeldin Hassan E. Konozy* \\ Biotechnology Park, Africa City of Technology, Khartoum, Sudan
}

Received: June 23, 2017

Revised: October 19, 2017

Accepted: October 22, 2017

\begin{abstract}
The genus Erythrina, collectively known as "coral tree", are pantropical plants, comprising of more than 112 species. Since the early 1980s, seven of these have been found to possess hemagglutinating activity, although not yet characterized. However, around two dozen galactose-binding lectins have been isolated and fully characterized with respect to their sugar specificity, glycoconjugates agglutination, dependence of activity on metal ions, primary and secondary structures and stability. Three lectins have been fully sequenced and the crystal structures of the two proteins have been solved with and without the haptenic sugar. Lectins isolation and characterization from most of these species usually originated from the seeds, although the proteins from other vegetative tissues have also been reported. The main objective of this review is to summarize the physicochemical and biological properties of the reported purified Erythrina lectins to date. Structural comparisons, based on available lectins sequences, are also made to relate the intrinsic physical and chemical properties of these proteins. Particular attention is also given to the proposed biological significance of the lectins from the genus Erythrina.
\end{abstract}

Keywords: Legume, Erythrina Species, Lectin, Properties, Structures, Physiological role.

\section{INTRODUCTION}

The family Fabaceae [Leguminosis] is considered the third largest family of the flowering plants, with around 800 genera and 20,000 species [1]. The genus Erythrina belongs to the legume group, which is widely distributed along the tropical and subtropical areas of the world. Many phytochemical compounds such as alkaloids, flavonoids, saponins and lectins have been isolated from this genus and received special attention in research and biotechnology. Lectins are defined as plant proteins possessing at least one non-catalytic domain that binds reversibly to specific mono or oligosaccharides [2]. The history of plant legume lectins began in 1890, after the discovery of the toxic robin from the barks of the black locust tree Robinia pseudoacacia [3]. The genus Erythrina was not subjected to lectin investigation until sixty years later, when the first two species Erythrina bogotensis and Erythrina galuca were reported by Maleka [4]. At that time, the hemagglutination features of lectins were attributed to their specific carbohydrate binding activity [5]. It was not until the eighties, when the influx of lectins data from different species of Erythrina was obtained as a result of the introduction of modern biochemistry and affinity chromatography techniques, which made the systematic and structural isolation of numerous lectins possible. To date and to the best of our knowledge, only around 34 different Galactose/N-acetylgalactosamine specific lectins from species of Erythrina have been detected and characterized. Initial reports indicated only the mere presence of hemagglutination activity of these proteins as in case of Erythrina falcata and Erythrina guineensis [6,7]. Later, full report on molecular and structural elucidation of these proteins was available in case of Erythrina corallodendron [ECorL] and Erythrina caristagalli lectins (ECL) [8, 9] (Table 1). In this review article, we attempt to provide a detailed description on lectins from the genus Erythrina, with regards to their isolation, purification, and characterization, with special focus on their biochemical, biophysical, physiological and structural characteristics compared to related lectins from other legume genera.

\footnotetext{
* Address correspondence to this author at the Biotechnology Park, Africa City of Technology, Khartoum, Sudan; Tel: +2490912387107;
} E-mail: ehkonozy@yahoo.com 
Table 1. List of abbreviations used for Erythrina species as well as the isolated lectin.

\begin{tabular}{|c|c|c|c|}
\hline Source & Lectin & Source & Lectin \\
\hline E. abssynicia & EAbsL & E. indica leaves & EILL \\
\hline E. americana & EAL & E. indica seeds & EISL \\
\hline E. arborescens & EArbL & E. latissima & ELatL \\
\hline E. berieroma & EBerL & E. lithosperma & ELitL \\
\hline E. bogotensis & EBL & E. lysistemon & ELysL \\
\hline E. caffra & ECafL & E. poeppiginiana & EPoeL \\
\hline E. caristagalli & ECL & E. perrieri & EPL \\
\hline E. corallodendron & ECorL & E. rubrinervia & ERL \\
\hline E. costaricensis & ECosL & E. senegalensis & ESenL \\
\hline E. edulis & EEL & E. speciosa & ESpecL \\
\hline E. falcata & EFalL & E. steyermarkii & ESteL \\
\hline E. flabelliformis & EFL & E. stricta & ESL \\
\hline E. fusco & EFucL & E. suberosa & ESubL \\
\hline E. glauca & EGlaL & E. sumatrana & ESumL \\
\hline E. globocaliz & EGL & E. variegata & EVL \\
\hline E. guineensis & EGuiL & E. velutina & EVA \\
\hline \multirow[t]{2}{*}{ E. humena } & EHL & E. vespertilio & EVesL \\
\hline & & E. zeyheri & EZL \\
\hline
\end{tabular}

\section{OCCURENCE AND PURIFICATION}

Galactose-specific lectins from Erythrina (ELs) were isolated mainly from seed extracts; in some studies they were isolated from other vegetative parts such as leaves, barks, nods and pods. In all reported studies, the extraction methods were achieved with saline and/or saline buffered solutions. In some cases, the method proceeded by a de-fatting step to ensure removal of lipids and pigments. The yield of the purified lectins varied from less than $1 \%$, as in case of $E$. arborescens and E. senegalensis [10,11] to as high as $90 \%$ as in E. americana [12]. The reason behind these variations was ascribed to the use of human stroma O-RBCs- Sephadex resin, as it is believed that lectins possess higher affinity toward complex glycans than simple mono or disaccharides [13]. Seed lectin content varied between the different Erythrina species; for example E. suberosa seeds contain only $2 \mathrm{mg}$ lectin per $100 \mathrm{~g}$ seeds flour, while around $1540 \mathrm{mg}$ lectin per $100 \mathrm{~g}$ seeds was purified from E. variegate [14] (Table 2). Around 2-3 lectin isoforms were detected by isoelectric focusing (Table 3), which were in coherent with other legume lectins. The occurrence of multiple isolectins in legume seeds seems to be related to physiological roles, though yet to be clearly disclosed, and could be extended to include plenty of other plant families such as Cucurbitaceae [15 - 17]. The use of affinity matrices leads to the purification of all isolectins into a single homogeneous peak. However, separation of these isoforms would have been achieved if a salting-out fractionation step use ammonium sulfate [0-40\%, 40-60\% and 60-80\% respectively] was introduced in the purification procedure, as in case of E. abyssinica lectins, where three galactose specific lectins were isolated [18]. Vegetative tissues from legume lectins would also contain more than one lectin, which may differ from seed lectins (e.g. bark lectins from Sophora japonica) [19]. In case of E. indica leaf lectin (EILL), a single lectin could be detected, which differs from its counterpart seed lectin (EISL) with regard to native molecular weight, isoelectric point and several other physiochemical properties. It is, however, yet to be determined if the protein is encoded by the same gene as the seed lectins [20].

Table 2. Purification table of Erythrina lectins. UA= unavailable data.

\begin{tabular}{|l|c|c|c|l|c|}
\hline \multicolumn{1}{|c|}{ ELs } & $\begin{array}{c}\text { Conc. } \\
{[\mathbf{m g} / \mathbf{1 0 0 g} \text { flour] }]}\end{array}$ & $\begin{array}{c}\text { Yield } \\
{[\%]}\end{array}$ & Specific Titer[HUA/mg $\left.{ }^{\mathbf{1}}\right]$ & \multicolumn{1}{|c|}{ Affinity Medium } & Reference \\
\hline EAL & 49 & 91 & 28.51 & Human Stroma O RBCs-Sephadex-25G & {$[12]$} \\
\hline EArbL & 40 & 0.23 & 7.8 & Acid treated ECD-Sepharose-6B & {$[10]$} \\
\hline ECafL & $133-166$ & $65-80$ & UA & Lactose-divinylsulphone activated Sepharose-4B & {$[58]$} \\
\hline ECL & $166-180$ & $74-75$ & 210 & Con A-Sepharose & {$[21]$} \\
\hline
\end{tabular}




\begin{tabular}{|c|c|c|c|c|c|}
\hline ELs & $\begin{array}{c}\text { Conc. } \\
{[\mathrm{mg} / 100 \mathrm{~g} \text { flour }]}\end{array}$ & \begin{tabular}{c|c|} 
Yield \\
{$[\%]$}
\end{tabular} & Specific Titer $\left[\mathrm{HUA} / \mathrm{mg}^{1}\right]$ & Affinity Medium & Reference \\
\hline ECorL & $125-166$ & $50-70$ & UA & Lactose-divinylsulphone activated Sepharose-4B & [58] \\
\hline ECosL & 103 & UA & 75.4 & O- $\alpha$-D-galactosyl polyacrylamide & {$[22]$} \\
\hline EEL & 121 & UA & 57.1 & $\mathrm{O}-\alpha$-D-galactosyl polyacrylamide & [24] \\
\hline EILL & 0.63 & UA & 37200 & Lactamyl-Seralose-4B & {$[20]$} \\
\hline EISL & $\begin{array}{c}120 \\
40\end{array}$ & $\begin{array}{l}\mathbf{U A} \\
\mathbf{U A} \\
\end{array}$ & $\begin{array}{l}\text { UA } \\
\text { UA }\end{array}$ & $\begin{array}{l}\text { O- } \alpha \text {-D-galactosyl polyacrylamide } \\
\text { Acid treated ECD-Sepharose-6B }\end{array}$ & $\begin{array}{l}{[80]} \\
{[10]}\end{array}$ \\
\hline ELatL & $100-117$ & $60-70$ & UA & Lactose-divinylsulphone activated Sepharose-4B & {$[58]$} \\
\hline ELitL & 40 & UA & UA & Acid treated ECD-Sepharose-6B & {$[10]$} \\
\hline ELysL & $\begin{array}{c}5.1 \\
167-200\end{array}$ & \begin{tabular}{c|}
40 \\
$60-75$
\end{tabular} & $\begin{array}{r}75 \\
\mathbf{U A} \\
\end{array}$ & \begin{tabular}{|l|} 
Lactose-Agarose \\
Lactose-divinylsulphone activated Sepharose-4B
\end{tabular} & $\begin{array}{l}{[34]} \\
{[58]}\end{array}$ \\
\hline ERL & 152 & UA & 86.79 & $\mathrm{O}-\alpha$-D-galactosyl polyacrylamide & {$[23]$} \\
\hline ESenL & 6.22 & 0.5 & 9.83 & Lactose-Sepharose-4B & {$[11]$} \\
\hline ESpecL & 250 & 66 & 773 & Lactose-Sepharose-4B & {$[25]$} \\
\hline ESubL & 2 & UA & UA & Acid treated ECD-Sepharose-6B & {$[10]$} \\
\hline EVL & $\begin{array}{c}540 \\
1540\end{array}$ & $\begin{array}{c}43 \\
83.8 \\
\end{array}$ & $\begin{array}{c}64 \\
434.4 \\
\end{array}$ & $\begin{array}{l}\text { Acid-treated Sepharose-6B } \\
\text { Lactose-Sepharose-6B }\end{array}$ & $\begin{array}{l}{[39]} \\
{[14]}\end{array}$ \\
\hline EVesL & 220 & UA & UA & Lactose-Sepharose-6B & [39] \\
\hline
\end{tabular}

\section{PHYSIOCHEMICAL AND ANALYTICAL CHARACTERISTICS}

\subsection{Biophysical Characteristics}

Legume lectins are essentially metallo-proteins and Erythrina lectins are no exception, they are all $\mathrm{Ca}^{2+}{\text { and } \mathrm{Mn}^{2+}-}^{-}$ dependent proteins. Demetallization of the protein has shown that not all tested lectin activities were affected by the presence of chelating agent ( $50 \mathrm{mM}$ or $100 \mathrm{mM}$ EDTA). This suggests that the metal ions might be buried deep inside the lectin structure and might not affect the binding of the saccharide conjugates. Examples of such lectins are from $E$. indica, E. caristagalli, E. edulis, E. rubrinervia, and E. americana [10, 12, 21 - 24] (Table 3). Almost all tested Erythrina lectins were not affected by the presence of EDTA with the exception of E. speciosa and E. senegalensis, where complete inactivation was observed when the protein was treated with chelating agent. The activity of the protein was restored when both $\mathrm{Ca}^{2+}$ and $\mathrm{Mn}^{2+}$ were added [11, 25]. To emphasize the role of the metal ion in legume lectins, it is found that the binding of the sugar moiety relies on the simultaneous presence of $\mathrm{Ca}^{2+}$ and a transition metal ion, $\mathrm{Mn}^{2+}$ as in our case. This might be explained by the ability of the calcium ions to stabilize the carbohydrate binding via structural water molecules. The structural analysis of ECorL and ECL showed that each metal ion is attached to four extremely conserved residues and two water molecules. The calcium ion binds Asp129, Phe131, Asn133 and Asp136, while the manganese ion binds Glu127, Asp129, Asp136 and His142. The two aspartate residues form a bridge between the two metal ions $[9,26,27]$. Other residues such as Trp135 are believed to be required for the tight binding of $\mathrm{Ca}^{2+}$ and $\mathrm{Mn}^{2+}$ to the lectin. This was confirmed by site directed mutagenesis, where mutant-ECorL (W135A) in which Trp135 was replaced by Ala135, resulted in loss of the metal ions upon dialysis and rendered the mutant protein inactive [28]. The structural role of metal ions was studied on the demetalized concanavlin A (Con A) structure, refined at $2.5 \AA$ and its subsequent metal ions activation. The study showed that binding of calcium and zinc/cobalt ions is controlled by the key event isomerization of the peptide bond Ala207-Asp208 from trans to cis, and the formation of the transitioned $\mathrm{Ca}^{2+}$ binding site by the side chain residues of Glu8, Asp10 and His24. In case of W135A, the release of metal ion occurs due to the increased mobility of the 132-136 loops rather than being coupled directly to the isomerization process observed for Con A. Binding of $\mathrm{Zn}^{2+}$ or $\mathrm{Co}^{2+}$ in Con A initiates the movement of Asp19 and alters the disordered Pro13-Pro23 loop that result in transforming the lectin from "unlocked" metal free state into "locked" metals bound form, hence enabling carbohydrate recognition [29, 30]. It was also proposed that the presence of high sugar concentration in the absence of metal ions stabilizes the unlock conformation and shift it toward a lock conformation that has higher degree of folding [31], which may be extended to explain in part how binding the monosaccharide can protect against chemotropic exposure. It is noteworthy to say that binding sugar moiety i.e. galactose, to both ECL and ECorL does not bring any conformational change of the D-loop within the binding site of the metalized protein unlike Con A. Hence, the structural effect of the carbohydrate binding to the demetalized ELs remains to be investigated. 
Lectins are known for their high stability under harsh conditions. Erythrina lectins retain full activity upon exposure to buffer solutions ranging in $\mathrm{pH}$ from 6-10. However, at $\mathrm{pH} 11$, the protein is completely inactive and in acidic buffer solutions, the proteins retain only around $25 \%$ activity $[11,14,20,25]$. On the other hand, full activity was observed in the $\mathrm{pH}$ range of 2-10 for E. indica, E. poeppigiana and E. steyermarkii lectins [10,32]. Konozy et al. investigated the effect of $\mathrm{pH}$ on Erythrina lysistemon lectin (ELysL) secondary structure by using Circular Dichroism (CD). It was found that a wide range of conformational changes occurred within the $\mathrm{pH}$ range tested. The maximum secondary structure was observed at $\mathrm{pH} 8.0$ and the minimum at $\mathrm{pH} 2.0$ [33]. Thermal studies on some of Erythrina lectins showed that they were stable at wide range of temperatures, up to $70^{\circ} \mathrm{C}$ as in the case of ELysL [34]. In general, most of the tested lectins were stable up to $50^{\circ} \mathrm{C}$ and rapidly lose their activity to the point of complete abolishment upon reaching the next temperature thermo interval (Table 3). The high stability of lectins might be attributed to the proteins glycosylated, and evidence suggested that glycosylation elevates numerous physical protein instabilities, which occur upon exposure to extreme environmental conditions. Studying the role of glycosylation using Molecular Dynamics (MD) simulations on the structure of E. corallodendron glycosylated-native and N-glycan devoid-recombinant lectins ( $n$ ECorL and $r$ ECorL) showed that glycosylation provides higher thermal stability to $n$ ECorL because it affects the side-chain packing of the lectin. This leads to reduction of non-polar solvent accessibility of surface area (ASA) of $n$ ECorL compared to $r$ ECorL, hence the marginally higher stability [35].

Table 3. Analytical and some physiochemical properties of Erythrina lectins. Data obtained either by ultracentrifugation or using pre-calibrated gel filtration Sephadex column, * Data obtained by SDS-PAGE, UA= unavailable data.

\begin{tabular}{|c|c|c|c|c|c|c|c|c|c|c|c|c|c|c|c|c|}
\hline \multirow[t]{2}{*}{ ELs } & \multirow{2}{*}{$\begin{array}{c}\text { Native } M_{r} \text { s } \\
\text { [kDa] }\end{array}$} & \multirow{2}{*}{$\begin{array}{c}\text { Protomer } M_{r}^{*} \\
{[\mathrm{kDa}]}\end{array}$} & \multirow[t]{2}{*}{$p I$} & \multirow[t]{2}{*}{$\varepsilon_{1 \mathrm{~cm}}{ }^{1 \%}$} & \multicolumn{2}{|c|}{\begin{tabular}{|c|} 
Metal Ion \\
[atom/mole]
\end{tabular}} & \multirow[t]{2}{*}{ pH } & \multirow{2}{*}{\begin{tabular}{|c|}
$\mathbf{T}$ \\
{$\left[^{\circ} \mathbf{C}\right]$} \\
\end{tabular}} & \multirow{2}{*}{$\begin{array}{c}\text { N. Sugar } \\
{[\%]}\end{array}$} & \multicolumn{6}{|c|}{ Ratio of Natural N-Glycan } & \multirow[t]{2}{*}{ Ref. } \\
\hline & & & & & $\mathrm{Ca}^{+2}$ & $\mathbf{M a}^{+2}$ & & & & Man & GlcNAc & $\mathbf{X y l}$ & Fuc & Gal & Arb & \\
\hline EAL & 57 & 30 & $6.3,6.6$ & 26.42 & UA & UA & UA & $25-50$ & 7 & 3 & 4 & 1 & 1 & - & - & {$[12]$} \\
\hline EArbL & UA & 28 & UA & UA & UA & UA & UA & UA & 5.7 & UA & UA & UA & UA & - & - & [10] \\
\hline ECafL & 59.3 & 30 & UA & UA & UA & UA & UA & UA & 5.6 & 3.8 & 1.1 & 1.1 & 1 & - & - & {$[58]$} \\
\hline ECL & 56.8 & 27,28 & UA & UA & 1.9 & 1 & UA & UA & 4.5 & 3.5 & 1.9 & 1 & 1 & - & - & {$[21]$} \\
\hline ECorL & 60.5 & 28 & UA & UA & UA & UA & UA & UA & 5.5 & \begin{tabular}{|l|}
3.3 \\
\end{tabular} & 2.5 & 1 & 1 & - & - & [58] \\
\hline ECosL & 56 & 27.2 & $6.48,6.84,6.97$ & 26.42 & $5-6$ & UA & UA & UA & 3.64 & UA & UA & UA & UA & UA & UA & [22] \\
\hline EEL & 56 & 27.5 & $5.4,5.5$ & UA & $6-7$ & traces & UA & UA & 7.8 & \begin{tabular}{|l|}
$\mathbf{U A}$ \\
\end{tabular} & UA & UA & UA & UA & $\mathbf{U A}$ & [24] \\
\hline EFL & UA & 29 & UA & UA & UA & UA & UA & UA & UA & \begin{tabular}{|l|}
$\mathbf{U A}$ \\
\end{tabular} & UA & UA & UA & \begin{tabular}{|l|}
$\mathbf{U A}$ \\
\end{tabular} & UA & [58] \\
\hline EFucL & UA & 28 & UA & UA & UA & UA & UA & UA & UA & UA & UA & UA & UA & UA & UA & [81] \\
\hline EGL & UA & 28 & UA & UA & UA & UA & UA & UA & UA & \begin{tabular}{|l|}
$\mathbf{U A}$ \\
\end{tabular} & UA & UA & UA & UA & $\mathbf{U A}$ & [81] \\
\hline EHL & UA & 29 & UA & UA & UA & UA & UA & UA & UA & UA & UA & UA & UA & UA & $\mathbf{U A}$ & [81] \\
\hline EILL & 58 & 30,33 & 7.6 & 12.5 & UA & UA & 7 & $25-55$ & UA & UA & UA & UA & UA & UA & UA & [20] \\
\hline EISL & 68 & 30,33 & $\begin{array}{c}4.83,5.09 \\
5.44\end{array}$ & UA & $2.9-3.5$ & $1.8-2.3$ & $3-9$ & $25-50$ & 4.5 & \begin{tabular}{|l|l|}
8.8 \\
\end{tabular} & 2.9 & 3.7 & 3 & 1.7 & 3.3 & {$[10]$} \\
\hline ELatL & 61.98 & 32,33 & UA & UA & UA & UA & $7.5-10.5$ & $25-70$ & 9 & 3 & 0.8 & 1.2 & 1 & - & - & {$[58]$} \\
\hline ELitL & UA & 26,28 & UA & UA & UA & UA & UA & UA & 4.1 & \begin{tabular}{|l|l|} 
UA \\
\end{tabular} & UA & $\mathbf{U A}$ & UA & \begin{tabular}{|l|}
$\mathbf{U A}$ \\
\end{tabular} & UA & [10] \\
\hline ELysL & 58 & 30 & $5.2-5.8$ & 17 & UA & UA & $7.5-10.5$ & $25-70$ & 6.2 & 3 & 1 & 1.2 & 1 & - & - & [34] \\
\hline EPoeL & 50 & 21,25 & UA & UA & UA & UA & $2-10$ & $40-70$ & UA & \begin{tabular}{|l|l|} 
UA \\
\end{tabular} & UA & $\mathbf{U A}$ & UA & \begin{tabular}{|l|}
$\mathbf{U A}$ \\
\end{tabular} & UA & [32] \\
\hline EPL & & 29,30 & UA & UA & UA & UA & UA & UA & UA & \begin{tabular}{|l|} 
UA \\
\end{tabular} & UA & $\mathbf{U A}$ & UA & UA & $\mathbf{U A}$ & [58] \\
\hline ERL & 62 & 29.5 & $5.19,5.02,5.12$ & 16.04 & 16 & 1 & UA & UA & UA & \begin{tabular}{|l|} 
UA \\
\end{tabular} & UA & $\mathbf{U A}$ & UA & \begin{tabular}{|l|l|} 
UA \\
\end{tabular} & UA & [23] \\
\hline ESenL & 62 & 30 & UA & UA & UA & UA & $6-10$ & $25-65$ & 6.5 & \begin{tabular}{|l|} 
UA \\
\end{tabular} & UA & UA & UA & \begin{tabular}{|l|}
$\mathbf{U A}$ \\
\end{tabular} & UA & \begin{tabular}{|l|}
{$[11]$} \\
\end{tabular} \\
\hline ESpecL & 58 & 27.1 & $5.8,6.1$ & 14.5 & UA & UA & 6- 9.6 & $25-65$ & UA & \begin{tabular}{|l|} 
UA \\
\end{tabular} & UA & UA & UA & UA & UA & [25] \\
\hline ESteL & 50 & 25 & UA & UA & UA & UA & $2-10$ & $40-70$ & UA & \begin{tabular}{|l|} 
UA \\
\end{tabular} & UA & UA & UA & \begin{tabular}{|l|}
$\mathbf{U A}$ \\
\end{tabular} & UA & [32] \\
\hline ESL & UA & 28 & UA & UA & UA & UA & UA & \begin{tabular}{l|l}
$\mathbf{U A}$ \\
\end{tabular} & UA & \begin{tabular}{|l|} 
UA \\
\end{tabular} & UA & UA & UA & \begin{tabular}{|l|} 
UA \\
\end{tabular} & UA & \begin{tabular}{|l|}
{$[53]$} \\
\end{tabular} \\
\hline ESubL & UA & 28 & UA & UA & UA & UA & UA & UA & 6.8 & \begin{tabular}{|l|} 
UA \\
\end{tabular} & UA & $\mathbf{U A}$ & UA & \begin{tabular}{|l|}
$\mathbf{U A}$ \\
\end{tabular} & UA & [10] \\
\hline EVL & 60 & 33,35 & UA & UA & UA & UA & $6-9$ & $25-60$ & 9 & 3 & 1 & 1.1 & \begin{tabular}{|l|}
1.1 \\
\end{tabular} & - & - & \begin{tabular}{|l|}
{$[14]$} \\
\end{tabular} \\
\hline EVesL & 59 & 32 & $4.8,5.3$ & UA & UA & UA & UA & UA & 9.7 & \begin{tabular}{|l|}
7.5 \\
\end{tabular} & 2 & 2.5 & 0.5 & 12.5 & - & [39] \\
\hline EZL & UA & 29 & UA & UA & UA & UA & UA & UA & UA & UA & UA & $\mathbf{U A}$ & UA & \begin{tabular}{|l|} 
UA \\
\end{tabular} & UA & [58] \\
\hline
\end{tabular}




\subsection{Molecular Mass and Sequence Analysis}

ELs are assembled from one chain protomer of molecular weight ranged between 27 to $35 \mathrm{kDa}$, which in turn form a dimer of native molecular weight 56-68 $\mathrm{kDa}$. In most cases, the protomers are identical, however hetero dimers are also common (Table 3). The heterogeneity of the subunits' molecular masses occurs due to differences in the primary structure and/or the variation in the number of the N-glycan chains attached and their structural composition. The chemical structural differences between isolectins were extensively studied on EVLs. Yamaguchi and his colleagues attributed the difference to the substitution at seven amino acids between A-subunit $M_{r} 35 \mathrm{kDa}$ (Gly30, Asn46, Glu71, Tyr106, Val111, Glu202 and Glu206) and B-subunit $M_{r}$ 33kDa (Asp30, Asp46, Gln71, Ser106, Ile111, Gln202 and Gln206). However, upon treatment with the deglycosylating agent trifluoromethanesulfonic acid, both subunits' molecular weights were decreased to $31 \mathrm{kDa}$, which was explained by the loss of the glycan chains [36]. The single polypeptide chain of ELs protomer is composed of 230-294 amino acid residues, which again are within the range of amino acid compositions of legume lectin. Structurally, all ELs are rich in acidic, hydroxyl and aliphatic amino acids residues, with low content of methionine (4-8 residue/Mole lectin) and no cysteine residues, except in the case of $E$. rubrinervia lectin (ERL), where 8 residues per mole lectin is reported [23] (Table 4). All purified Erythrina lectins reported so far exhibit similar physicochemical properties. They share similarities in the N-terminal amino acid sequences. 16 out of the 18 available sequences of the primary structure of lectin have valine as the first amino acid residue. Only two species display alanine in the N-terminus amino acid. It is to be noted that glutamine and threonine are conserved at position 2 and 3 of the N-terminal sequence (Table 5).

\subsubsection{The Exceptional Erythrina lysistemon Seed Lectin}

Although the sequence/structure of E. lysistemon lectin (ELysL) remained to be elucidated, ELysL showed few but clear distinctive features that deviate from its ELs counterparts. All ELs exist in dimeric forms, mainly consist of $\beta$ sheets and loops, and lack the ability to bind ligands other than the carbohydrates. Regardless of the similarities in physiochemical properties, the amino acid composition profile and N-terminal identity match the related ELs. ELysL can exist both as dimer and tetramer with molecular weights of 58 and $120 \mathrm{kDa}$ respectively. At physiological conditions the higher concentration of the former predominates. This is a distinctive feature observed in Con A and Tamarindus indica lectin EMtL $[16,34]$, that indicates the presence of tetramer interface motifs. ELysL is also distinguished due to its high $\alpha$-helices secondary structure content. Denaturing studies monitored by CD and hemagglutination assays indicated that the unfolding event of ELysL is not a two state process as with ECorL. However, it includes an intermediate molten globule-like structure that retains around $80 \%$ of activity. Fluorescence and amino acid modification studies indicated that tryptophan did not display any role in binding sugar, a feature shared by EILL [20] and EspecL [25]. In the case of ELysL, tryptophan is located within a hydrophobic region that is designated for adenine binding. Although ECorL and Con A possess the sequence for adenine binding, the ability for such ligand binding remained exclusive to ELysL among ELs. Such characteristic feature is also shared by other adenine binding lectins, such as winged bean agglutinin [WBA-I and WBA-II] and the tetramer Dolichos biflorus lectin (DBL), where the $\alpha$-helix in the protein 3D structure forms a hydrophobic site by direct overlap between the two monomers of the lectin $[33,37,38]$.

\section{STRUCTURE OF ERYTHRINA LECTINS}

\section{1. $N$-Glycan Structure}

All reported ELs are glycoproteins (natural sugar content 3.6-10\%) (Table 3). The $N$-glycan attached to the lectins is composed mainly of a complex combination of Mannose, Xylose, Fucose and $N$-acetyl-glucosamine with different ratios and orders. However, the presence of Galactose was reported in E. vespertillo lectin [39] while Arabinose and Galactose were detected in E. indica lectin glycan composition [10] (Table 3). In some studies, Con A was used to determine if the non-reduced terminal of $N$-glycan is a $D$-mannose, and was used to purify lectins in some cases [22, 34]. The presence of Xylose is believed to be a signature for plant glycoproteins, as it is believed that the glycans of animal proteins lack the Xylose moiety [40]. Ashford et al stipulated that the $N$-linked glycan of ECL is characterized firstly by the substitution of the common core of the pentasaccharides [Man $\alpha 3$-[Man $\alpha 6$ ]-Man $\beta 4$ NAcGlc $\beta 4 N A c G l c]$ of $N$-glycoproteins by $\beta$ - $D$-Xylose $(1 \rightarrow 2)$ attached to the $\beta$-mannosyl residue and secondly by the presence of $\alpha$ - $L$-Fucose $(1 \rightarrow 3)$ linked to the reducing end of GlcNAc residue. About $90 \%$ of the branched $N$-glycan was of the following sequence $\quad[\alpha-D-\operatorname{Man}[1 \rightarrow 3] \alpha-D-\operatorname{Man}[1 \rightarrow 6]]-\beta-D-X y l-[1 \rightarrow 2]-\beta-D-$ Man- $\beta-D$-GlcNAc- $[1 \rightarrow 4]-[\alpha-L-$ Fuc- $[1 \rightarrow 3]]-D$ GlcNAc [41]. X-ray crystallography studies enabled the generation of an electron density map of the six N-glycan 
residues out of the seven in the 3D crystal structure of ECL, as the X-ray diffraction resolution was suitable enough to generate such a model [9].

The hepta- $N$-glycan of ECorL was found to be $[\alpha-D-\operatorname{Man}(1 \rightarrow 3)-[\alpha-D-\operatorname{Man}(1 \rightarrow 6)]-\beta-D-X y 1-(1 \rightarrow 2)]-\beta-D-$ $\operatorname{Man}(1 \rightarrow 4)-\beta-D$-GlcNAc- $(1 \rightarrow 4)-[\alpha-L$-Fuc- $(1 \rightarrow 3)]-D$-GlcNAc], and the heterogeneity of the oligosaccharide moieties occurs due to the lack of Fucose in some of the chains attached to ECorL [42, 43]. The glycosylation site is confined to three amino acid residues, namely Asn17, Asn46 and Asn113. The probable site for attachment of $N$-glycan to ECL is Asn113, while ECorL and EVA (E. velutina lectin) have two glycosylation sites, the Asn17 and Asn113 in each protomer. However, the crystal structure of ECorL illustrated only the $N$-glycan joined to Asn 17 , and the side-chain of this site is structurally compensated by the conformational changes and the formation of hydrogen bonds in $r$ ECorL, without affecting the backbone of the site. On the other hand, the three EVL isolectins [with A and B protomers] have different glycosylation patterns and sites. The A-subunit is glycosylated at Asn17, Asn46 and Asn113, whereas the Bsubunit is glycosylated at only two sites, Asn17 and Asn113 due to the substitution of Asn47 by Asp47 [9, 27, 36]. Molecular dynamic simulation on ECorL showed that the $N$-glycan is very mobile, interacts predominantly with the solvent, and it can also form transient non-covalent interaction with the protein surface, at distant amino acids residues (Lys55 and Tyr53), allowing more flexibility of the loops [35, 44 - 46].

\subsection{D Structure}

Legume lectins by definition are a family of proteins, which have the same tertiary and importantly variable quaternary structure. X-ray crystallography studies of Erythrina lectins started in 1987 when X-ray diffraction pattern studies were performed on ECorL [46]. This was followed by other successful crystallization and structure determinations of both ECorL and ECL.

ELs, like all other legume lectins are strictly composed of anti-parallel $\beta$-sheets, loops, and no $\alpha$-helices, which form a structure known as "jelly roll". The $\beta$-sheets are divided into three groups, six standard flat back sheets, seven standard curved front sheets and three-to-five small S sheets. In both ECorL and ECL, the first and second back $\beta$ sheets are connected and formed via $\mathrm{N}$ - and C-terminals. Conversely, the $\mathrm{N}$ - and C-terminals of Con A are formed by the front $\beta$-sheets. The loops are constructed by around $51 \%$ of the total amino acids residues. The main hydrophobic core is located between the front and back sheets and a second hydrophobic nucleus is generated between the front sheets and the extended three loops, forming the metal ion binding site as well as the carbohydrate recognition domain (Fig. 1) [8,9]. Erythrina lectins possess a unique mode of quaternary association different from the canonical mode of dimerization seen in Con A, or any other legume lectins. They can only exist in the form of dimers linked via handshake association. Such, mode of association was first seen in ECorL and hence called "ECorL-Type". Many attempts have been made to identify the characteristics of the dimer interface. Elgavish and Shaanan report that the legume lectin dimer is established and stabilized by the chemical composition of the amino acids present in the dimer interface rather than the sequence of the amino acids [47]. Using a graph-spectral algorithm to identify the side-chains and their cluster centers in combination with the traditional multiple sequence alignment indicated that the quaternary mode of association in legume lectins could be determined by their sequence. The ECorL-type of dimerization has an interface called X3 that allows the overlap of the $\beta$-sheets of each monomer to form the handshake. Mapping the structurally conserved residues identified in the X3 interface cluster revealed that both SFE and VIKYD motifs located at positions 60-70 and 170 of the amino acid sequence are responsible for the association. ECorL exclusively exists as a dimer and cannot form a tetramer because its sequence lacks the interface determinants at the $\mathrm{N}$ - and $\mathrm{C}$-terminals that allow the tetramer formation [48]. It was proposed earlier that the hindrance of the canonical dimer formation in ECorL was due to the glycosylation at Asn17 of the protein N-terminal. However, since other lectins such as ECL, WBA-I and WBA-II exhibit the same handshake mode of dimerization but with a different glycosylation site far from the tetramer interface motifs, it was concluded that the ECorL-type of dimerization occurs due to protein intrinsic factors [9, 44, 49, 50]. Further analysis of the native and recombinant ECorL crystal structures indicated that there is no significant difference except the absence of the $N$-glycan in $r$ ECorL. Both adopt the handshake dimerization, in fact glycosylation only affects the overall thermal stability of the nECorL over the rECorL, not the dimerization properties.

\subsection{Carbohydrate Binding and Sugar Specificity}

Binding of carbohydrate to lectins is attributed to a shallow groove located on the surface of the molecule known as the carbohydrate binding domain "CBD". ELs are classified as Hololectins which contain two identical or very similar binding sites [51]. ELs are basically Galactose/Galactose derivative specific lectins (Table 6). The structural features of 
carbohydrate recognition in ELs were determined from several X-ray crystal structures of both ECorL and ECL, native, recombinant and mutant models. In brief, the $\mathrm{CBD}$ is formed by four loops (A, B, C and D) [52]. Loops $\mathrm{A}, \mathrm{B}$ and $\mathrm{C}$ contain the highly conserved residues (Ala88, Asp89, Gly107 and Asn133) which form the binding site of carbohydrate in legume lectin, while loop D is highly variable and its amino acid residues determine the carbohydrate specificity of each lectin. Unlike Man/Glc specific lectin, binding of sugar moieties to ECorL does not induce any conformational change in loop D owing to the presence of water molecules, which would be replaced by a hydroxyl group of the incoming ligand.

Although the binding of lactose to ECL is mediated via different structural arrangements than ECorL [9], the obtained crystals of ECorL in complex with mono and disaccharides reveal that the sugar recognition is taking place in the same manner, with a slight difference presented in additional formation of one direct hydrogen bond and an extra Van der Waals interaction are required when binding Lactose/ $N$-acetyllactosamine [27]. On the other hand, the structural/thermodynamic relationship studies performed in ECorL binding to disaccharides offer a great number of binding options compared to monosaccharides, which can't be detected in the X-ray static model [53].

For further studies on the importance of the affinity site amino acids in ECorL, which are likely to affect the affinity and/or the specificity of lectin towards certain sugar moieties, a series of engineered mutant lectins were achieved. The same hemagglutinating activity and affinity towards galactose were obtained after substituting Tyr108 and Pro134Trp135 residues with equivalent peptide residues found in the peanut agglutinin PNA affinity site (Thr108 and Ser-GluTyr-Asn) and soybean agglutinin SBA (Ser-Trp) [54]. Lower affinity towards GalNAc and almost no affinity for Methyl- $\beta$ - $D$-dansylgalactosaminide [Me $\beta$ GalNDns] are noticed in mutants with the PNA substitution peptide. These results suggest that the differences in sugar specificity between ECorL, SBA and PNA are due to the steric hindrance caused by the additional amino acids found in PNA [55]. According to Adar and her colleagues, Trp135 plays a vital role in enhancement of the affinity binding of lectin to Me $\alpha$ GalNDns [28]. Mutation at position 219 showed that the native Gln219 side-chain provides a conformational flexibility that allows several favorable interactions with LacNAc, hence enhancing the binding affinity [56]. Testing the hemagglutinating activity of the T106G mutant and the subsequent crystallization of lectin with Gal/GalNAc showed remarkable reduction of the lectin affinity towards galactose and, to the contrary, enhancement of GalNAc affinity, these findings are explained by the formation of an additional direct hydrogen bond between GalNAc and the adjacent Gly107 [57].

\section{GLYCOCONJUGATES AND CELL TYPING}

Despite the overall physiochemical and the structural similarities between lectins isolated from different species of the genus Erythrina, their ability and extent to which they agglutinate cells and glycoconjugates varies. Most of them agglutinate human RBCs and in some cases display more affinity toward certain blood types [10, 58]. While many of them can agglutinate rabbit erythrocytes, their ability to agglutinate other animal blood cells varies drastically [23, 24]. Although agglutination against protease-treated RBCs provided better accessibility to the bound membrane glycoconjugates and enhanced the binding affinity of lectins by several folds, their agglutination affinity remained the same. In this context, it is to be noted that the best hapten inhibitor might differ from the membrane bound saccharide receptor recognized by lectin. Hence, many attempts have been made to redefine the carbohydrate specificity of ECorL and ECL, which has been achieved and extended to higher affinity binding of glycoconjugates with the polyvalent terminal glycoepitops Gal $\beta 1-4$ GlcNAc and Fuc 22 Gal $\beta 4$ GlcNAc $\beta-[13,56,59]$. Agglutination occurs when a homogenous carbohydrate-lectin cross-linked precipitate is formed between lectins and multivalent glycosides bearing a specific sugar, such as LacNAc [60]. This process can be influenced by many factors including the relative amount of the bi, tri, and tetraantennary carbohydrate on the cell surface, which determines the valency of the carbohydrate. Moreover, the size of the lectin monomer is also considered an influencing factor for the oligosaccharide valency. Hence, the chain length in biantennary molecules can determine whether tetravalent lectins such as SBA and Con A can form a precipitation complex, and in return has no effect when it comes to divalent lectins such as EIL, EArbL and Ricinus communis agglutinin-I [RCA] [61]. For the divalent lectins and unlike Con A, the presence of bisecting GlcNAc in the biantennary complex-type oligosaccharides has little or no effect on the binding activity and the valencies of the carbohydrate [62, 63]. In a mixture of divalent Erythrina lectins, unique lattices with tri- and tetra-antennary complextype oligosaccharides are formed with almost the same affinity but different stability. Comparison of the $n \mathrm{ECorL}$ with $r$ ECorL provides evidence for a heterotypic carbohydrate-carbohydrate interaction between the $N$-glycan of ECorL and the triantennary glycoprotein, which has led to the stabilization of a specific lectin-carbohydrate cross-linked complex that cannot be formed by $r \mathrm{ECorL}$ [64]. 
A)

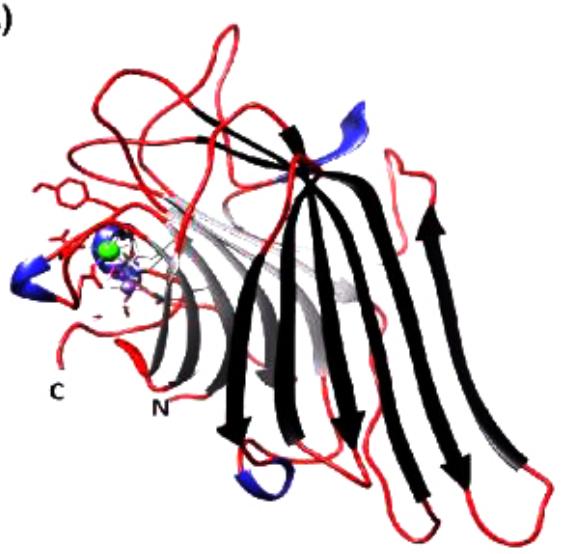

B)

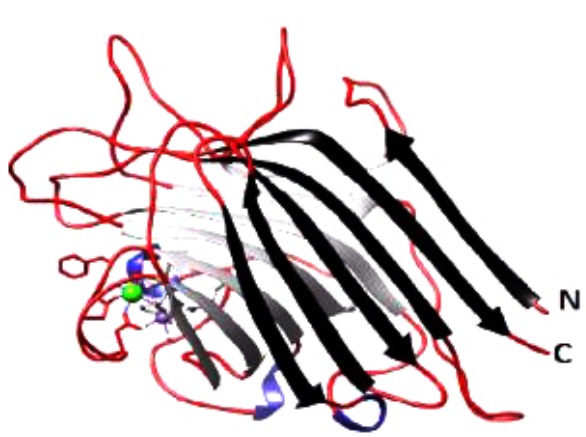

C)

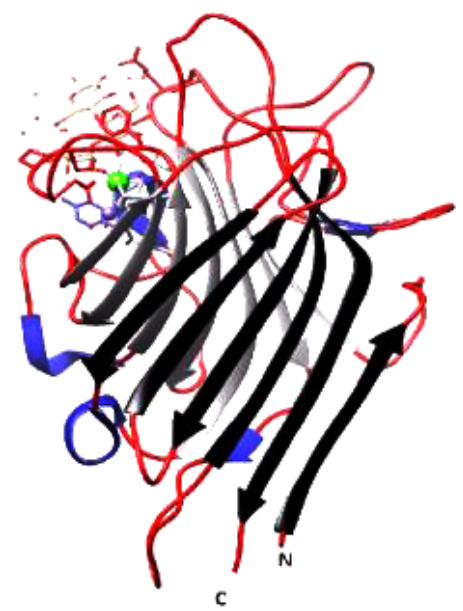

1)

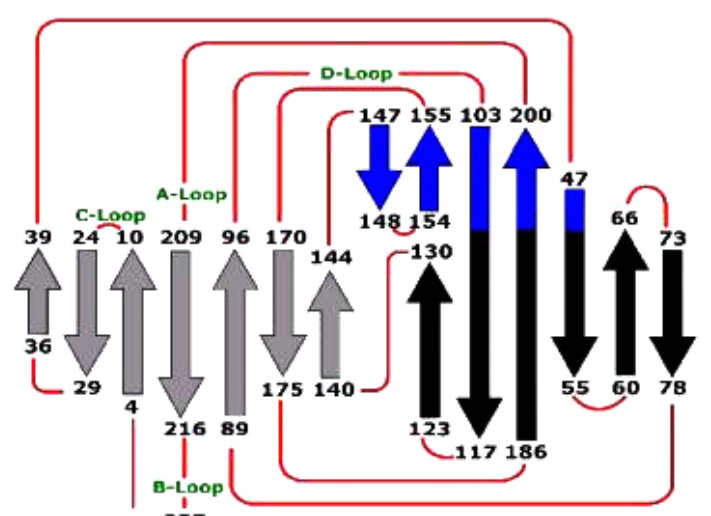

$N \stackrel{237}{C}$

2)

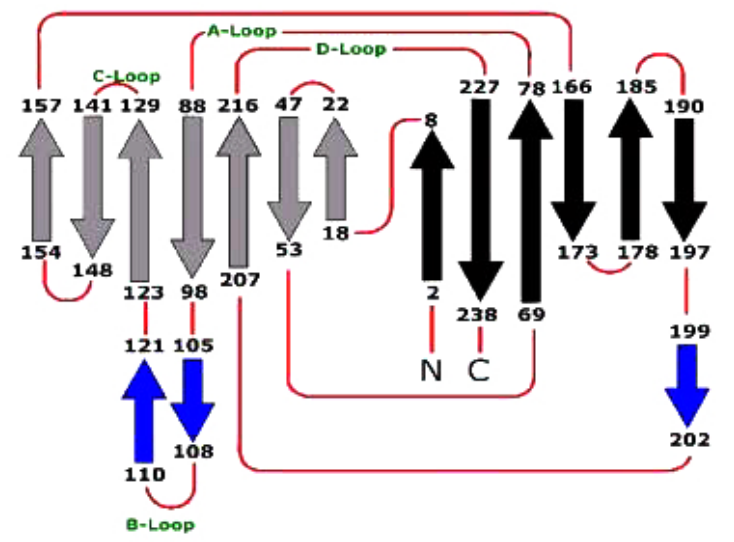

3)

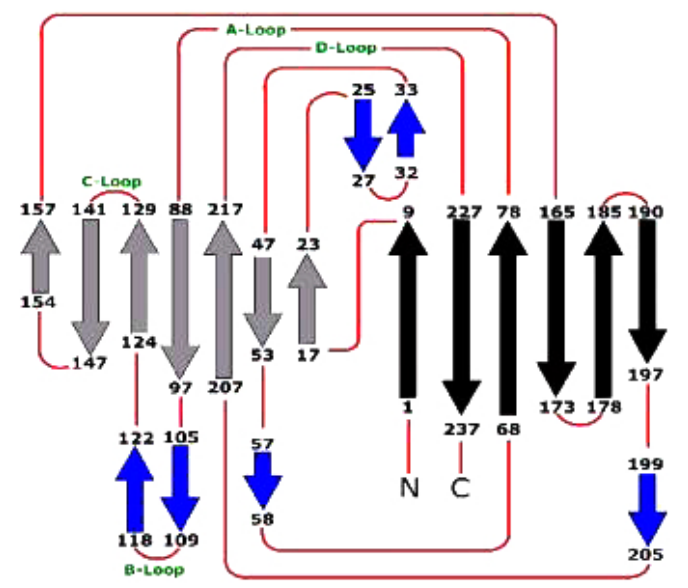

Fig. (1). A, B and C are the monomers of Con A, ECorL and ECL crystallized with hapten ligand [pdb files: 1c57, 1axy and 1gzc respectively]. The 3D- monomer structures were opened and edited using UCSF-Chimera 1.8 software [1 - 3]. are the topology diagram of each lectin deduced from the 3D-structure from each lectin. Black arrows represent the $\beta$-back black sheets, the light gray arrows represent the $\beta$-front sheets and the small blue arrows are the S-sheets while the red lines represent the loops. A, B, C, and Dloops contains the amino acids responsible for sugar binding.

Table 4. Amino acid composition of Erythrina lectins.

\begin{tabular}{|c|c|c|c|c|c|c|c|c|c|c|c|c|c|c|c|c|c|c|c|}
\hline \multirow{2}{*}{$\begin{array}{c}\text { Amino Acid } \\
\text { [Residue/Mole] }\end{array}$} & \multicolumn{19}{|c|}{ Erythrina sp. Lectin } \\
\hline & EAL & ECafL & ECL & ECorL & ECosL & EEL & EFL & EHL & EILL & EISL & ELatL & ELysL & EPL & ERL & ESenL & ESL & EVL & EVesL & EZL \\
\hline Asp & 33 & 62 & 62 & 60 & 57 & 52 & 61 & 62 & 69 & 63 & 62 & 62 & 66 & 65 & 64 & 58 & 96 & 65 & 63 \\
\hline Glu & 25 & 58 & 55 & 58 & 63 & 49 & 57 & 60 & 63 & 61 & 55 & 59 & 50 & 64 & 62 & 53 & 58 & 52 & 60 \\
\hline Ser & 38 & 49 & 47 & 47 & 53 & 35 & 46 & 48 & 41 & 51 & 50 & 51 & 45 & 71 & 53 & 57 & 44 & 48 & 48 \\
\hline
\end{tabular}


(Table 4) contd.....

\begin{tabular}{|c|c|c|c|c|c|c|c|c|c|c|c|c|c|c|c|c|c|c|c|}
\hline \multirow{2}{*}{$\begin{array}{c}\text { Amino Acid } \\
\text { [Residue/Mole] }\end{array}$} & \multicolumn{19}{|c|}{ Erythrina sp. Lectin } \\
\hline & EAL & ECafL & ECL & ECorL & ECosL & EEL & EFL & EHL & EILL & EISL & ELatL & ELysL & EPL & ERL & ESenL & ESL & EVL & EVesL & EZL \\
\hline Gly & 48 & 41 & 39 & 41 & 50 & 32 & 39 & 41 & 50 & 38 & 41 & 41 & 36 & 47 & 40 & 40 & 36 & 40 & 39 \\
\hline His & 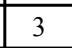 & 10 & 8 & 9 & 14 & 14 & 11 & 9 & 11 & 10 & 10 & 9 & 10 & 6 & 12 & 12 & 12 & 12 & 11 \\
\hline Arg & 14 & 12 & 11 & 11 & 12 & 7 & 12 & 12 & 15 & 11 & 12 & 11 & 11 & 1 & 11 & 14 & 8 & 13 & 12 \\
\hline Thr & 40 & 41 & 43 & 41 & 44 & 33 & 44 & 42 & 48 & 44 & 38 & 39 & 38 & 28 & 45 & 43 & 42 & 43 & 43 \\
\hline Ala & 40 & 40 & 40 & 40 & 42 & 33 & 46 & 40 & 57 & 40 & 39 & 41 & 43 & 22 & 45 & 36 & 40 & 43 & 40 \\
\hline Pro & 47 & 36 & 39 & 39 & 37 & 36 & 36 & 34 & 44 & 34 & 37 & 43 & 30 & 23 & 45 & 35 & 12 & 39 & 35 \\
\hline Tyr & 29 & 17 & 20 & 18 & 14 & 18 & 18 & 17 & 21 & 22 & 17 & 19 & 18 & 10 & 19 & 17 & 16 & 20 & 18 \\
\hline \begin{tabular}{|l|} 
Val \\
\end{tabular} & 50 & 34 & 42 & 33 & 33 & 33 & 30 & 32 & 39 & 42 & 33 & 32 & 33 & 20 & 36 & 35 & 44 & 44 & 30 \\
\hline Met & 8 & 4 & 6 & 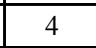 & 6 & 3 & 4 & 6 & 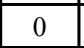 & 6 & 4 & 6 & 4 & 6 & 6 & 4 & 4 & 6 & 6 \\
\hline \begin{tabular}{|l|} 
Cys \\
\end{tabular} & 0 & 0 & 0 & 0 & 0 & 0 & 0 & 0 & 0 & 0 & 0 & 0 & 0 & 8 & 0 & 0 & 0 & 0 & 0 \\
\hline Ile & 36 & 31 & 30 & 29 & 24 & 20 & 22 & 26 & 35 & 29 & 28 & 28 & 24 & 17 & 32 & 24 & 28 & 31 & 25 \\
\hline Leu & 53 & 37 & 37 & 36 & 34 & 26 & 34 & 35 & 37 & 37 & 39 & 36 & 33 & 18 & 39 & 34 & 34 & 38 & 31 \\
\hline \begin{tabular}{|l|} 
Phe \\
\end{tabular} & 35 & 29 & 28 & 28 & 16 & 1 & 32 & 31 & 31 & 29 & 29 & 29 & 30 & 11 & 28 & 34 & 24 & 28 & 31 \\
\hline Lys & 36 & 20 & 20 & 19 & 24 & 89 & 21 & 19 & 26 & 18 & 17 & 20 & 20 & 22 & 29 & 18 & 30 & 22 & 17 \\
\hline Trp & 0 & 0 & 0 & 0 & 15 & 17 & 0 & 0 & 0 & 13 & 0 & 0 & 0 & 16 & 13 & 0 & 6 & 9 & 0 \\
\hline Total & 535 & 521 & 527 & 513 & $\begin{array}{l}538 \\
\end{array}$ & 498 & 513 & \begin{tabular}{|l|}
514 \\
\end{tabular} & $\begin{array}{l}588 \\
\end{array}$ & 548 & 511 & 526 & 491 & \begin{tabular}{|l|}
461 \\
\end{tabular} & 579 & 514 & \begin{tabular}{|l|l|}
534 \\
\end{tabular} & 553 & \begin{tabular}{|l|}
509 \\
\end{tabular} \\
\hline Reference & [12] & [58] & [21] & [12] & [22] & [24] & [58] & {$[58]$} & {$[20]$} & {$[10]$} & [58] & [58] & [58] & [23] & [11] & [58] & [14] & [39] & {$[58]$} \\
\hline
\end{tabular}

Table 5. Comparison between the amino acid sequences of the studied Erythrina sp. lectins with the known N-terminals. The score and the identities of each lectin were calculated using BLASTP 2.6.0+ online software from [ncbi.nIm.nih.gov] against the N-terminal sequence of ECorL [26].

\begin{tabular}{|c|c|c|c|c|c|}
\hline \multirow[t]{2}{*}{ Source } & \multirow[t]{2}{*}{ N-terminal Sequence } & \multirow{2}{*}{$\begin{array}{l}\text { Score } \\
\text { [bits] }\end{array}$} & \multicolumn{2}{|c|}{ Identities } & \multirow{2}{*}{ Seq. Ref. } \\
\hline & & & & $\%$ & \\
\hline ECafL & V-E-T-I-S-F-S-F-S-E-F-E-P-G-N- & 51.1 & $15 / 15$ & 100 & [58] \\
\hline $\mathbf{E C L}$ & V-E-T-I-S-F-S-F-S-E-F-E-P-G-N- & 51.1 & $15 / 15$ & 100 & [53] \\
\hline ECorL & V-E-T-I-S-F-S-F-S-E-F-E-P-G-N-D-N-L-T-L-Q-G-D-S-L-P- & - & - & & [26] \\
\hline ECosL & A-E-T-M-S-F-S-F- & 21.8 & $6 / 7$ & 85 & [22] \\
\hline EFL & V-E-T-I-S-F-S-F-S-E-F-E-P-G-N- & 51.1 & $15 / 15$ & 100 & [58] \\
\hline EFucL & V-E-T-I-S-F-N-F-S-E-F-E-P-G-N-N-D-L-T-L-Q-G-A-A-L-I- & 66.8 & $20 / 25$ & 80 & [81] \\
\hline EGL & A-E-T-M-S-F-S-F-S-Q-F-Q-P-G-N-N-D-L-T-L-Q-G-V- & 54.9 & $16 / 21$ & 76 & [81] \\
\hline EHL & V-E-T-I-S-F-S-F-S-E-F-E-P-G-N- & 51.1 & $15 / 15$ & 100 & [58] \\
\hline EILL & V-E-T-I-S-F-S-F-S-E-F-E-A-G-N-D-X-L-T-Q-E-G-A-A- & 56.6 & $18 / 22$ & 82 & {$[20]$} \\
\hline EISL & V-E-T-I-S-F-S-F-S-E-F-E-A-G-N-D-X-L-T-Q-E-G-A-A- & 56.6 & $18 / 22$ & 82 & [20] \\
\hline ELatL & V-E-T-I-S-F-S-F-S- & 31.2 & $9 / 9$ & 100 & {$[58]$} \\
\hline ELysL & V-E-T-I-S-F-S-F-S-E-F-E-P-G-N- & 51.1 & $15 / 15$ & 100 & {$[58]$} \\
\hline EPL & V-E-T-I-S-F-S-F-S-K-F-E-A-G- & 38.4 & $12 / 15$ & 85 & [58] \\
\hline ESpecL & V-E-T-I-S-F-S-F-S-E-F-E- & 41.8 & $12 / 12$ & 100 & [25] \\
\hline ESL & V-E-T-I-S-F-S-F-S- & 31.2 & $9 / 9$ & 100 & [58] \\
\hline EVL & V-E-T-I-S-F-S-F-S-E-F-E-A-G-N-D-X-L-T-L-Q-G-A-A-L-I- & 66.4 & $21 / 25$ & 84 & [36] \\
\hline EVesL & V-E-T-I-S-F-S-F-S-E-F-E-A-G-N-D-S-L-T-L-Q-G-A-S-L-P- & 72.7 & $23 / 26$ & 88 & [39] \\
\hline \begin{tabular}{|l|l} 
EZL & \\
\end{tabular} & V-E-T-I-S-F-S-F-S-E-F-E-P-G-N- & 46.9 & $14 / 15$ & 93 & [58] \\
\hline
\end{tabular}

Table 6. Relative inhibition of Erythrinas lectins activity using mono and disaccharides. Solid gray blocks indicate the most potent inhibitory sugar for each lectin. 
(Table 6) contd....

\begin{tabular}{|c|c|c|c|c|c|c|c|c|c|c|c|c|c|c|c|c|c|c|c|c|c|c|c|c|c|c|}
\hline & \multicolumn{26}{|c|}{ Relative Inhibitory Activity of Erythrina Lectins } \\
\hline & EArbL & ECafL & ECosL & ECL & ECorL & EEL $\mathrm{I}$ & EFL & EFucL & EGL & EHL & EILL & EISL & ELatL & ELitL & ELysL & EPoeL & EPL & ERL & ESenL & ESpecL & ESteL & ESL & ESubL & EVL & EVesL & EZL \\
\hline Metheyl- $\alpha$ - $D$ - galactoside & 2.0 & 4.0 & 1.0 & 2.8 & 1.5 & 0.4 & 2.0 & $\mathrm{nT}$ & $\mathrm{nT}$ & 1.0 & 0.7 & 2.0 & 1.8 & 2.0 & 1.5 & $\mathrm{nT}$ & 1.0 & 2.2 & 0.5 & 2.0 & $\mathrm{nT}$ & 2.0 & 2.0 & $\mathrm{nT}$ & 2.0 & 1.0 \\
\hline Metheyl- $\beta$ - $D$ - galactoside & 1.0 & 1.0 & 0.5 & 1.0 & 1.0 & 2.2 & 0.5 & $\mathrm{nT}$ & $\mathrm{nT}$ & 1.0 & 0.7 & 4.0 & 1.4 & 1.0 & 1.3 & $\mathrm{nT}$ & 1.0 & 2.2 & $\mathrm{nT}$ & 1.0 & $\mathrm{nT}$ & 0.5 & 1.0 & $\mathrm{nT}$ & 1.0 & 1.0 \\
\hline$p$-Nitrophenyl- $\alpha$ - $D$-galactoside & 8.0 & 30.5 & NT & 3.4 & 1.6 & nT & 3.5 & $\mathrm{nT}$ & nT & 3.0 & 0.5 & 2.0 & 3.3 & 8 & 2.5 & $\mathrm{nT}$ & 1.7 & nT & $\mathrm{nT}$ & 5.0 & $\mathrm{nT}$ & 1.75 & 2.0 & $\mathrm{nT}$ & 10 & 2.0 \\
\hline$p$-Nitrophenyl- $\beta$ - $D$-galactoside & 2.0 & 14 & 5.0 & 6.8 & 3.2 & 8.4 & 7.0 & $\mathrm{nT}$ & $\mathrm{nT}$ & 10 & 0.5 & 8.0 & 10 & 4 & 6.0 & $\mathrm{nT}$ & 7.0 & 8.3 & $\mathrm{nT}$ & nT & $\mathrm{nT}$ & 6.0 & 4.0 & $\mathrm{nT}$ & 20.5 & 8.0 \\
\hline$D$-Galactosamine & $\mathrm{nT}$ & $\mathrm{nT}$ & 0.1 & 0.7 & nT & \begin{tabular}{l|l}
0.3 \\
\end{tabular} & \begin{tabular}{|l|}
$\mathrm{nT}$ \\
\end{tabular} & $\mathrm{nT}$ & $\mathrm{nT}$ & $\mathrm{nT}$ & 1.7 & 0.1 & nT & $\mathrm{nT}$ & nT & nT & $\mathrm{nT}$ & nT & $N I$ & 0.1 & $\mathrm{nT}$ & $\mathrm{nT}$ & $\mathrm{nT}$ & $\mathrm{nT}$ & 0.3 & $\mathrm{nT}$ \\
\hline$D$-Lactose & 4.0 & 1.0 & 2.0 & 6.8 & 2.7 & 14.9 & 7.4 & + & + & 4.0 & 5 & 4.0 & 7.5 & 4 & 1.8 & 2 & 4.0 & 3.7 & 1.0 & 40 & 8 & 8 & 4.0 & 1.9 & 8.0 & 3.0 \\
\hline$N$-acetyllactosamine & $N I$ & 33 & nT & 33.8 & 19 & $\mathrm{nT}$ & 35 & $\mathrm{nT}$ & $\mathrm{nT}$ & 17 & 2.5 & $\mathrm{nT}$ & 35 & $N I$ & 20 & $\mathrm{nT}$ & 17 & nT & $\mathrm{nT}$ & 20 & $\mathrm{nT}$ & 35 & $N I$ & $\mathrm{nT}$ & $\mathrm{nT}$ & 17 \\
\hline$D$-Raffinose & 0.5 & $\mathrm{nT}$ & 0.5 & 1.9 & $\mathrm{nT}$ & 0.5 & $\mathrm{nT}$ & $\mathrm{nT}$ & $\mathrm{nT}$ & $\mathrm{nT}$ & 1.7 & 1.0 & nT & 0.5 & 0.7 & 1.0 & $\mathrm{nT}$ & nT & $\mathrm{nT}$ & nT & 2.0 & $\mathrm{nT}$ & 1.0 & $\mathrm{nT}$ & 1.0 & $\mathrm{nT}$ \\
\hline$D$-Melibiose & 1.0 & $\mathrm{nT}$ & $N I$ & $\mathrm{nT}$ & $\mathrm{nT}$ & \begin{tabular}{l|l}
1.8 \\
\end{tabular} & $\mathrm{nT}$ & $\mathrm{nT}$ & $\mathrm{nT}$ & $\mathrm{nT}$ & 1.7 & 2.0 & $\mathrm{nT}$ & 1.0 & nT & $\mathrm{nT}$ & $\mathrm{nT}$ & 3.6 & $\mathrm{nT}$ & 2.0 & $\mathrm{nT}$ & $\mathrm{nT}$ & 2.0 & $\mathrm{nT}$ & 2.0 & $\mathrm{nT}$ \\
\hline$D$-Fucose & 0.2 & 0.4 & NT & 0.75 & $\mathrm{nT}$ & $\mathrm{nT}$ & 0.23 & $N I$ & $N I$ & 0.23 & $\mathrm{nT}$ & nT & nT & \begin{tabular}{|l|} 
\\
\end{tabular} & $\mathrm{nT}$ & $\mathrm{nT}$ & $\mathrm{nT}$ & $\mathrm{nT}$ & $\mathrm{nT}$ & $\mathrm{nT}$ & $\mathrm{nT}$ & 0.44 & 0.25 & $\mathrm{nT}$ & $\mathrm{nT}$ & 0.23 \\
\hline$D$-Xylose & $N I$ & $\mathrm{nT}$ & $N I$ & $N I$ & nT & nT & $\mathrm{nT}$ & $N I$ & NI & $\mathrm{nT}$ & nT & $\mathrm{nT}$ & $\mathrm{nT}$ & nT & nT & $\mathrm{nT}$ & $\mathrm{nT}$ & nT & $\mathrm{nT}$ & nT & nT & $\mathrm{nT}$ & nT & $\mathrm{nT}$ & $\mathrm{nT}$ & nT \\
\hline References & [10] & [58] & [22] & [21] & [58] & [24] & {$[58]$} & {$[81]$} & [81] & {$[58]$} & \begin{tabular}{|l|l|}
$20]$ \\
\end{tabular} & [10] & [58] & {$[10]$} & [34] & [32] & {$[58]$} & [23] & [11] & [25] & [32] & [58] & {$[10]$} & [14] & [39] & {$[58]$} \\
\hline
\end{tabular}

Since the formation of lectin-carbohydrate lattices provides a high degree of specificity and the glycosylation patterns of many cellular and serum glycoproteins undergo alternation during many cellular processes under pathological and pathogenic conditions, rapid growth of exogenous lectin applications was evident. Many ELs have a mitogenic effect on human peripheral blood lymphocytes but do not stimulate mouse thymocytes and splenocytes [21, $32,58]$. ECL was considered as a marker to monitor glycosylation changes during the differentiation of lymphocytes and embryonic cells [65]. It is also considered as a differentiation marker for increased $\alpha$-fetoprotein-E2 in hepatocellular carcinoma and other malignancies [66]. It was applied to enrich heterogenic human natural killer (NK) cells via negative selection and was proved to be more effective than using monoclonal antibodies [67], and to differentiate between feline monocytes and lymphocytes [68]. It was also used recently as a natural platform for culture and differentiation of stem cells [69], and suggested as a therapeutic agent that selectively targets neurotoxin A from Clostridium botulinum [70]. EVA was investigated for potential use as a prognostic marker in primary central nervous system tumors [71]. Koley proposed a possible application for ELitL in forensic science as an anti-LH marker that can be applied along with the ABO genotype system to settle paternity disputes [72]. In the agricultural field, EIL was considered a potent anti-insect compound against melon fruit fly, that significantly influences the normal growth, development and metabolism of the fly [73].

\section{PROPOSED PHYSIOLOGICAL FUNCTIONS}

Although the physiochemical and the molecular structure of many legume lectins have been resolved and well understood, elucidation of the exact physiological functions and biochemical mechanisms are still in their infancy stages. During the early days of lectins discovery, they were hypothesized to act as storage proteins. However, the specificity of these proteins for sugars contradicts the previous hypothesis. Legume lectins play different roles, depending on their cellular and tissue localization as well as the plant developmental stage [74]. The main functions of seed legume lectins were thought to help in transportation and packaging, nitrogen fixation and recently, as defense molecules. Erythrina seed lectins and other similar seed legume lectins often reside within the protein bodies along with the hydrolytic enzymes and storage proteins. Alpha-galactosidase, $\alpha$-mannosidase, $N$-acetyl- $\beta$ - $D$-glucosaminidase and acid phosphatase were found to act as endogenous receptors for EISL under in vitro conditions. Elution of these proteins requires the haptenic sugar [75]. Extraction of lectin from crude seed extract resulted in the sudden drop in some of these enzymes activities, with $\alpha$-mannosidase being the most affected enzyme. Addition of lectin, at a gradual increment, restored up to $35 \%$ of the $\alpha$-mannosidase activity. Such results were not obtained when ConA was used instead of EiSL. These observations allowed hypothesizing an indirect role of EiSL in facilitating the initial hydrolytic attack upon germination and ultimately the growth of the embryo [76]. Following the germination cycle of E. velutina seeds for 21 days, lectin was characterized by a clear delay in degradation in concomitant with a one fold increase in its activity as opposed to other proteins [77]. A similar study was performed with E. corallodendron seedling to monitor lectin activity during germination, where increase in activity was also evident. However, it was hard to verify if the increase in lectin activity was due to the germination processes, as the protein content was not correlated with lectin activity [78]. A recent study on EAbsL isolectins profile during the seed germination of E. abssynicia, in relation to protein content, provided clues on the predicted role of each of the following isolectins, EAbsL-40, EAbsL-60 and EAbL-80. Both isolectins EAbL-60 and 80 were characterized by slow degradation whereas complete loss in activity of EAbsL-40 was achieved in the first three weeks of germination [79]. Among various interesting observations of plant lectins was the finding that some legume lectins interact more favorably with carbohydrates that were coupled to large hydrophobic or aromatic moieties than the sugar component alone. The subsequent discovery of the presence of a hydrophobic binding site independent of the sugar affinity pocket complicated the opened query on biological role of plant lectins. Besides ConA and Peanut lectin, Erythrina lysistemon seed lectin [ELysL] has also been shown to possess a hydrophobic site which binds adenine through an independent binding site [33]. Considering the overall preliminary 
studies so far, Erythrina lectins would most likely have crucial physiological role rather than being just transport or storage proteins.

\section{CONCLUSION}

The legume lectins are a family of sugar-binding proteins found in plants. Erythrina Lectins, for an example, constitute a distinctive subgroup among the legume lectins. They share similar structural and physicochemical features. However, there are apparent variations in properties such as affinity towards sugars, preference for agglutination of human and animal blood and lastly interactions with hydrophobic molecules. These differences might have an influence on the physiological roles from species to species, although such claim is yet to be drastically validated. Further molecular and structural studies are warranted on other Erythrina Lectins to establish their evolutionary changes and to understand their detailed mechanism of actions.

\section{ETHICS APPROVAL AND CONSENT TO PARTICIPATE}

Not applicable.

\section{HUMAN AND ANIMAL RIGHTS}

No Animals/Humans were used for studies that are base of this research.

\section{CONSENT FOR PUBLICATION}

Not applicable.

\section{CONFLICT OF INTEREST}

The authors declare no conflict of interest, financial or otherwise.

\section{ACKNOWLEDGEMENTS}

We are very grateful for Dr. Iswarduth Soojhawon, Walter Reed Army Institute of Research, Silver Spring, MD 20910, USA, for revising and editing the manuscript.

\section{REFERENCES}

[1] Smýkal P, Coyne CJ, Ambrose MJ, et al. Legume crops phylogeny and genetic diversity for science and breeding. Crit Rev Plant Sci 2015; 34(1-3): 43-104. [http://dx.doi.org/10.1080/07352689.2014.897904]

[2] Peumans WJ, Van Damme EJ. Lectins as plant defense proteins. Plant Physiol 1995; 109(2): 347-52. [http://dx.doi.org/10.1104/pp.109.2.347] [PMID: 7480335]

[3] Kocourek J. Historical background In: The lectins, properties, functions, and applications in biology and medicine Liener IE, Sharon N, Goldstein IJ, editors Orlando, FL : Academic Press. 1986. [http://dx.doi.org/10.1016/B978-0-12-449945-4.50010-5]

[4] Makela O. Studies in hemagglutinins of leguminosae seeds. Ann Med Exp Biol Fenn 1957; 35(Suppl. 11): 1-133. [PMID: 13444881]

[5] Watkins WM, Morgan WT. Neutralization of the anti-H agglutinin in eel serum by simple sugars. Nature 1952; 169(4307): 825-6. [http://dx.doi.org/10.1038/169825a0] [PMID: 14941057]

[6] Martin T, Bomchil G. Haemagglutinins in argentinean leguminosae seeds. Vox Sang 1966; 11(1): $54-8$. [http://dx.doi.org/10.1111/j.1423-0410.1966.tb04201.x] [PMID: 5906792]

[7] Lee DW, Tan GS, Liew FY. A survey of lectins in Southeast Asian leguminosae. Planta Med 1977; 31(1): 83-93. [http://dx.doi.org/10.1055/s-0028-1097497] [PMID: 840935]

[8] Shaanan B, Lis H, Sharon N. Structure of a legume lectin with an ordered N-linked carbohydrate in complex with lactose. Science 1991; 254(5033): 862-6. [http://dx.doi.org/10.1126/science.1948067] [PMID: 1948067]

[9] Turton K, Natesh R, Thiyagarajan N, Chaddock JA, Acharya KR. Crystal structures of Erythrina cristagalli lectin with bound N-linked oligosaccharide and lactose. Glycobiology 2004; 14(10): 923-9. [http://dx.doi.org/10.1093/glycob/cwh114] [PMID: 15201215]

[10] Bhattacharyya L, Das PK, Sen A. Purification and properties of D-galactose-binding lectins from some Erythrina species: Comparison of properties of lectins from E. indica, E. arborescens, E. suberosa, and E. lithosperma. Arch Biochem Biophys 1981; 211(1): 459-70. [http://dx.doi.org/10.1016/0003-9861(81)90478-1] [PMID: 6796000] 
[11] Kuku A, Odekanyin OO, Okonji RE. Physiochemical properties of a lactose specific lectin from the seeds of Erythrina senegalensis Ife. J Sci 2012; 14(1): 143-53.

[12] Ortega M, Sanchez C, Chacon E, et al. Purification and characterization of a lectin from Erythrina americana by affinity chromatography. Plant Sci 1990; 72(1): 133-40.

[http://dx.doi.org/10.1016/0168-9452(90)90195-T]

[13] Teneberg S, Angström J, Jovall PA, Karlsson KA. Characterization of binding of Gal beta 4GlcNAc-specific lectins from Erythrina cristagalli and Erythrina corallodendron to glycosphinogolipids. Detection, isolation, and characterization of a novel glycosphinglipid of bovine buttermilk. J Biol Chem 1994; 269(11): 8554-63.

[PMID: 8132581]

[14] Fukuda N, Hidaka T, Yomo H. Isolation and characterization of a lectin from Erythrina variegata (Linn) var. Orientalis Seed. Agric Biol Chem 1990; 54(2): 413-8.

[15] Swamy MJ, Marapakala K, Sultan NA, Kenoth R. Galactose-specific seed lectins from Cucurbitaceae. Curr Protein Pept Sci 2015; 16(1): 17-30. [http://dx.doi.org/10.2174/1389203716666150213155602] [PMID: 25692845]

[16] Osman ME, Awadallah AK, Konozy EH. Isolation purification and partial characterization of three lectins from Tamarindus indica seeds with a novel sugar specificity. Int J Plant Res 2016; 6(1): 13-9.

[17] Awadallah AK, Osman ME, Ibrahim MA, Bernardes ES, Dias-Baruffi M, Konozy EH. Isolation and partial characterization of 3 nontoxic dgalactose-specific isolectins from seeds of Momordica balsamina. J Mol Recognit 2017; 30(2) [http://dx.doi.org/10.1002/jmr.2582] [PMID: 27774692]

[18] Mohieddin S. Modulating effects of Erythrina abyssinica seed lectins on varying pathogenic bacteria and fungus (MS. thesis) Khartoum, Sudan: University of applied medical science, 2016.

[19] Van Damme EJ, Barre A, Rouge P, Peumans WJ. Molecular cloning of the bark and seed lectins from the Japanese pagoda tree (Sophora japonica). Plant Mol Biol 1997; 33(3): 523-36. [http://dx.doi.org/10.1023/A:1005781103418] [PMID: 9049272]

[20] Konozy EH, Mulay R, Faca V, et al. Purification, some properties of a D-galactose-binding leaf lectin from Erythrina indica and further characterization of seed lectin. Biochimie 2002; 84(10): 1035-43. [http://dx.doi.org/10.1016/S0300-9084(02)00003-2] [PMID: 12504284]

[21] Iglesias JL, Lis H, Sharon N. Purification and properties of a D-galactose/N-acetyl-D-galactosamine-specific lectin from Erythrina cristagalli. Eur J Biochem 1982; 123(2): 247-52. [http://dx.doi.org/10.1111/j.1432-1033.1982.tb19760.x] [PMID: 6978812]

[22] Perez G. Purification and characterization of a lectin from the seeds of Erythrina costaricensis. Int J Biochem Cell Biol 1995; $27(8)$ : 857-63. [http://dx.doi.org/10.1016/1357-2725(95)00039-R] [PMID: 7584621]

[23] Peña C, Villarraga F, Pérez G. A lectin from the seeds of Erythrina rubrinervia. Phytochemistry 1988; 27(4): 1045-8. [http://dx.doi.org/10.1016/0031-9422(88)80270-X]

[24] Pérez G. Isolation and characterization of a lectin from the seeds of Erythrina Edulis. Phytochemistry 1984; 23(6): 1229-32. [http://dx.doi.org/10.1016/S0031-9422(00)80431-8]

[25] Konozy EH, Bernardes ES, Rosa C, Faca V, Greene LJ, Ward RJ. Isolation, purification, and physicochemical characterization of a Dgalactose-binding lectin from seeds of Erythrina speciosa. Arch Biochem Biophys 2003; 410(2): 222-9. [http://dx.doi.org/10.1016/S0003-9861(02)00695-1] [PMID: 12573281]

[26] Adar R, Richardson M, Lis H, Sharon N. The amino acid sequence of Erythrina corallodendron lectin and its homology with other legume lectins. FEBS Lett 1989; 257(1): 81-5. [http://dx.doi.org/10.1016/0014-5793(89)81791-0] [PMID: 2806566]

[27] Elgavish S, Shaanan B. Structures of the Erythrina corallodendron lectin and of its complexes with mono- and disaccharides. J Mol Biol 1998; 277(4): 917-32.

[http://dx.doi.org/10.1006/jmbi.1998.1664] [PMID: 9545381]

[28] Adar R, Moreno E, Streicher H, Karlsson KA, Angström J, Sharon N. Structural features of the combining site region of Erythrina corallodendron lectin: Role of tryptophan 135. Protein Sci 1998; 7(1): 52-63. [http://dx.doi.org/10.1002/pro.5560070105] [PMID: 9514259]

[29] Bouckaert J, Loris R, Poortmans F, Wyns L. Crystallographic structure of metal-free concanavalin A at 2.5 A resolution. Proteins 1995; 23(4): 510-24. [http://dx.doi.org/10.1002/prot.340230406] [PMID: 8749847]

[30] Bouckaert J, Poortmans F, Wyns L, Loris R. Sequential structural changes upon zinc and calcium binding to metal-free concanavalin A. J Biol Chem 1996; 271(27): 16144-50.

[http://dx.doi.org/10.1074/jbc.271.27.16144] [PMID: 8663112]

[31] Brewer CF, Brown RD III, Koenig SH. Metal ion binding and conformational transitions in concanavalin A: A structure-function study. J Biomol Struct Dyn 1983; 1(4): 961-97. [http://dx.doi.org/10.1080/07391102.1983.10507497] [PMID: 6400908] 
[32] Quesada S, Nanne CI, González L. Lectins of Erythrina poeppigiana and Erythrina steyermarkii [Leguminosae]: Characterization and mitogenic effect. Rev Biol Trop 1998; 46: 1039-46.

[33] Konozy EH, Dafalla MB, Hsiao CD. Spectroscopic studies on Erythrina lysistemon seed lectin: Effect of denaturing agents on lectin quaternary structure. Protein Pept Lett 2006; 13(6): 581-6. [http://dx.doi.org/10.2174/092986606777145751] [PMID: 16842113]

[34] Konozy EH. Characterizaion of a D-galactose-binding lectin from seeds of Erythrina lysistemon. Glob Adv Res J Biochem Bioinfo 2012; 1(1): 7-18.

[35] Kaushik S, Mohanty D, Surolia A. Role of glycosylation in structure and stability of Erythrina corallodendron lectin (EcorL): A molecular dynamics study. Protein Sci 2011; 20(3): 465-81. [http://dx.doi.org/10.1002/pro.578] [PMID: 21432931]

[36] Yamaguchi O, Kimura M, Araki M, et al. Chemical structures of two subunits, A-subunit and B-subunit, of galactose-specific isolectins from Erythrina variegata seeds. J Biochem 1993; 114(4): 560-6. [http://dx.doi.org/10.1093/oxfordjournals.jbchem.a124216] [PMID: 8276768]

[37] Hamelryck TW, Loris R, Bouckaert J, et al. Carbohydrate binding, quaternary structure and a novel hydrophobic binding site in two legume lectin oligomers from Dolichos biflorus. J Mol Biol 1999; 286(4): 1161-77. [http://dx.doi.org/10.1006/jmbi.1998.2534] [PMID: 10047489]

[38] Srinivas VR, Acharya S, Rawat S, Sharma V, Surolia A. The primary structure of the acidic lectin from winged bean (Psophocarpus tetragonolobus): Insights in carbohydrate recognition, adenine binding and quaternary association. FEBS Lett 2000; 474(1): 76-82. [http://dx.doi.org/10.1016/S0014-5793(00)01580-5] [PMID: 10828455]

[39] Kortt AA. Characterization of a lectin from the seeds of Erythrina vespertilio. Phytochemistry 1986; 25(10): $2371-4$. [http://dx.doi.org/10.1016/S0031-9422(00)81698-2]

[40] Lis H, Sharon N. Biology and carbohydrates. Ginsburg VR, P.W., Eds., editor. New York: Wiley 1984.

[41] Ashford D, Dwek RA, Welply JK, et al. The $\beta 1 \rightarrow 2-\mathrm{D}$-xylose and $\alpha 1 \rightarrow 3$-L-fucose substituted N-linked oligosaccharides from Erythrina cristagalli lectin. Isolation, characterisation and comparison with other legume lectins. Eur J Biochem 1987; 166(2): $311-20$. [http://dx.doi.org/10.1111/j.1432-1033.1987.tb13516.x] [PMID: 3609010]

[42] Young NM, Watson DC, Yaguchi M, et al. C-terminal post-translational proteolysis of plant lectins and their recombinant forms expressed in Escherichia coli. Characterization of "ragged ends" by mass spectrometry. J Biol Chem 1995; 270(6): 2563-70. [http://dx.doi.org/10.1074/jbc.270.6.2563] [PMID: 7852319]

[43] Ashford DA, Dwek RA, Rademacher TW, Lis H, Sharon N. The glycosylation of glycoprotein lectins. Intra- and inter-genus variation in Nlinked oligosaccharide expression. Carbohydr Res 1991; 213: 215-27. [http://dx.doi.org/10.1016/S0008-6215(00)90610-4] [PMID: 1933938]

[44] Kulkarni KA, Srivastava A, Mitra N, et al. Effect of glycosylation on the structure of Erythrina corallodendron lectin. Proteins 2004; 56(4): 821-7. [http://dx.doi.org/10.1002/prot.20168] [PMID: 15281133]

[45] Naidoo KJ, Denysyk D, Brady JW. Molecular dynamics simulations of the N-linked oligosaccharide of the lectin from Erythrina corallodendron. Protein Eng 1997; 10(11): 1249-61. [http://dx.doi.org/10.1093/protein/10.11.1249] [PMID: 9514113]

[46] Saper MA, Lis H, Sharon N, Shaanan B. Crystallization and preliminary X-ray diffraction studies of the lectin from Erythrina corallodendron. J Mol Biol 1987; 193(4): 823-4. [http://dx.doi.org/10.1016/0022-2836(87)90363-9] [PMID: 3612795]

[47] Elgavish S, Shaanan B. Chemical characteristics of dimer interfaces in the legume lectin family. Protein Sci 2001; 10(4): 753-61. [http://dx.doi.org/10.1110/ps.44001] [PMID: 11274466]

[48] Brinda KV, Mitra N, Surolia A, Vishveshwara S. Determinants of quaternary association in legume lectins. Protein Sci 2004 ; 13(7): 1735-49. [http://dx.doi.org/10.1110/ps.04651004] [PMID: 15215518]

[49] Prabu MM, Sankaranarayanan R, Puri KD, et al. Carbohydrate specificity and quaternary association in basic winged bean lectin: X-ray analysis of the lectin at 2.5 A resolution. J Mol Biol 1998; 276(4): 787-96. [http://dx.doi.org/10.1006/jmbi.1997.1568] [PMID: 9500920]

[50] Manoj N, Srinivas VR, Surolia A, Vijayan M, Suguna K. Carbohydrate specificity and salt-bridge mediated conformational change in acidic winged bean agglutinin. J Mol Biol 2000; 302(5): 1129-37.

[http://dx.doi.org/10.1006/jmbi.2000.4111] [PMID: 11183779]

[51] Peumans WJ, Damme EJ. Plant lectins: Versatile proteins with important perspectives in biotechnology. Biotechnol Genet Eng Rev 1998; 15(1): 199-228. [http://dx.doi.org/10.1080/02648725.1998.10647956]

[52] Sharma V, Surolia A. Analyses of carbohydrate recognition by legume lectins: Size of the combining site loops and their primary specificity. J Mol Biol 1997; 267(2): 433-45.

[http://dx.doi.org/10.1006/jmbi.1996.0863] [PMID: 9096236] 
[53] Bradbrook GM, Forshaw JR, Pérez S. Structure/thermodynamics relationships of lectin-saccharide complexes: The Erythrina corallodendron case. Eur J Biochem 2000; 267(14): 4545-55. [http://dx.doi.org/10.1046/j.1432-1327.2000.01505.x] [PMID: 10880979]

[54] Arango R, Adar R, Rozenblatt S, Sharon N. Expression of Erythrina corallodendron lectin in Escherichia coli. Eur J Biochem 1992; 205(2): $575-81$. [http://dx.doi.org/10.1111/j.1432-1033.1992.tb16815.x] [PMID: 1572358]

[55] Arango R, Rodriguez-Arango E, Adar R, et al. Modification by site-directed mutagenesis of the specificity of Erythrina corallodendron lectin for galactose derivatives with bulky substituents at C-2. FEBS Lett 1993; 330(2): 133-6. [http://dx.doi.org/10.1016/0014-5793(93)80258-V] [PMID: 8365483]

[56] Moreno E, Teneberg S, Adar R, Sharon N, Karlsson KA, Angström J. Redefinition of the carbohydrate specificity of Erythrina corallodendron lectin based on solid-phase binding assays and molecular modeling of native and recombinant forms obtained by site-directed mutagenesis. Biochemistry 1997; 36(15): 4429-37.

[http://dx.doi.org/10.1021/bi962231h] [PMID: 9109650]

[57] Thamotharan S, Karthikeyan T, Kulkarni KA, et al. Modification of the sugar specificity of a plant lectin: Structural studies on a point mutant of Erythrina corallodendron lectin. Acta Crystallogr D Biol Crystallogr 2011; 67(Pt 3): 218-27. [http://dx.doi.org/10.1107/S0907444911004525] [PMID: 21358053]

[58] Lis H, Joubert FJ, Sharon N. Isolation and properties of N-acetyllactosamine-specific lectins from nine erythrina species. Phytochemistry 1985; 24(12): 2803-9. [http://dx.doi.org/10.1016/0031-9422(85)80004-2]

[59] Yang Z, Tsai MS, Wu JH, Herp A, Wu AM. Defining the carbohydrate specificities of Erythrina corallodendron lectin (ECorL) as polyvalent Galbeta1-4GlcNAc (II) > monomeric II > monomeric Gal and GalNAc. Chang Gung Med J 2008; 31(1): 26-43. [PMID: 18419051]

[60] Masaka R, Ogata M, Misawa Y, et al. Molecular design of N-linked tetravalent glycosides bearing N-acetylglucosamine, N,N'diacetylchitobiose and N-acetyllactosamine: Analysis of cross-linking activities with WGA and ECA lectins. Bioorg Med Chem 2010; 18(2): 621-9.

[http://dx.doi.org/10.1016/j.bmc.2009.12.006] [PMID: 20056550]

[61] Bhattacharyya L, Haraldsson M, Brewer CF. Precipitation of galactose-specific lectins by complex-type oligosaccharides and glycopeptides: studies with lectins from Ricinus communis (agglutinin I), Erythrina indica, Erythrina arborescens, Abrus precatorius (agglutinin), and Glycine $\max$ (soybean). Biochemistry 1988; 27(3): 1034-41. [http://dx.doi.org/10.1021/bi00403a028] [PMID: 3365364]

[62] Bhattacharyya L, Haraldsson M, Brewer CF. Concanavalin A interactions with asparagine-linked glycopeptides. Bivalency of bisected complex type oligosaccharides. J Biol Chem 1987; 262(3): 1294-9. [PMID: 3805021]

[63] Bhattacharyya L, Brewer CF. Formation of homogeneous carbohydrate-lectin cross-linked precipitates from mixtures of D-galactose/Nacetyl-D-galactosamine-specific lectins and multiantennary galactosyl carbohydrates. Eur J Biochem 1992; $208(1)$ : $179-85$. [http://dx.doi.org/10.1111/j.1432-1033.1992.tb17172.x] [PMID: 1511686]

[64] Gupta D, Arango R, Sharon N, Brewer CF. Differences in the cross-linking activities of native and recombinant Erythrina corallodendron lectin with asialofetuin. Evidence for carbohydrate-carbohydrate interactions in lectin-glycoprotein complexes. Biochemistry 1994; 33(9): 2503-8.

[http://dx.doi.org/10.1021/bi00175a020] [PMID: 7509639]

[65] Webb CG, Popliker M, Sharon N. Cell membrane and cancer. Amsterdam, Holland: Elsevier 1985.

[66] Kamei M, Misawa A, Arai J, Kamakura K, Taketa K. Erythrina cristagalli lectin-reactive alpha-fetoprotein-E2: a marker of hepatocellular carcinoma and other malignancies. Int J Biol Markers 1998; 13(1): 24-9.

[PMID: 9681296]

[67] Harris DT, Iglesias JL, Argov S, Toomey J, Koren HS. Heterogeneity of human natural killer (NK) cells: Enrichment of NK by negativeselection with the lectin from Erythrina cristagalli. J Leukoc Biol 1987; 42(2): 163-70. [PMID: 3474339]

[68] Whitehurst CE, Day NK, Gengozian N. Sugar competition assays reveal high affinity receptors for Erythrina cristigalli lectin on feline monocytes. J Immunol Methods 1990; 131(1): 15-24. [http://dx.doi.org/10.1016/0022-1759(90)90227-M] [PMID: 2380563]

[69] Mikkola M, Toivonen S, Tamminen K, et al. Lectin from Erythrina cristagalli supports undifferentiated growth and differentiation of human pluripotent stem cells. Stem Cells Dev 2013; 22(5): 707-16. [http://dx.doi.org/10.1089/scd.2012.0365] [PMID: 23106381]

[70] Duggan MJ, Quinn CP, Chaddock JA, et al. Inhibition of release of neurotransmitters from rat dorsal root ganglia by a novel conjugate of a Clostridium botulinum toxin A endopeptidase fragment and Erythrina cristagalli lectin. J Biol Chem 2002; $277(38)$ : $34846-52$. [http://dx.doi.org/10.1074/jbc.M202902200] [PMID: 12105193]

[71] Conrado FM, Furtado LE, Teixeira AH, Coutinho NL, Sampaio AH, Cavada BS, et al. Erythrina velutina and Bryothamnion seaforthii lectins binding to proteins of primery central nervous system tumers. J Canc Res Exp Onco 2012; 4(1): 21-6. 
[http://dx.doi.org/10.5897/JCREO12.004]

[72] Koley S. Forensic application of Erythrina lithosperma, an anti-LH lectin. J Punjab Acad Forensic Med Toxicol 2002; 2: 20-2.

[73] Singh K, Kaur M, Rup PJ, Singh J. Effects of indian coral tree, Erythrina indica lectin on eggs and larval development of melon fruit fly, Bactrocera cucurbitae. J Environ Biol 2009; 30(4): 509-14. [PMID: 20120488]

[74] Rudiger H. Inside-directed activities of plant lectins - a review. Lectins: Biology, biochemistry, clinical biochemistry 11. Hellerup, Denmark: Textop 1996; pp. 28-32.

[75] Konozy EH, Bhide SV. Towards a better understanding of the enigmatic biological function of plant lectin: Detection and identification of endogenous receptors for Erythrina indica seeds lectins. Macromol Ind J 2012; 8(2): 48-56.

[76] Kestwal RM, Konozy EH, Hsiao CD, Roque-Barreira MC, Bhide SV. Characterization of alpha-mannosidase from Erythrina indica seeds and influence of endogenous lectin on its activity. Biochim Biophys Acta 2007; 1770(1): 24-8. [http://dx.doi.org/10.1016/j.bbagen.2006.07.008] [PMID: 16935428]

[77] Oliveira JT, Moraes SM, Cavada BS, Moreira RA, Vascocelos IM. Protein and lectin mobilization during Erythrina velutina forma aurantiaca seed germination and seedling growth in the dark. Rev Bras Fisiol Vegetal 1998; 10(1): 25-30.

[78] Nir R. Sudakevitz D, Giloba-Garber N. Determination of Erythrina corallodendron lectin levels during plant growth and in normal as compared to aberrant seeds. Lectins: Biology, Biochemistry, Clinical Biochemistry. Hellerup, Denmark. Textop 1996; 11: 107-11.

[79] Mohamed M. Monitoring of Erythrina abyssinica and Abrus precatorius lectins expression during seed germination (MS. thesis) Khartoum, Sudan: Sudan academy of science; 2016

[80] Horejsí V, Tichá M, Novotný J, Kocourek J. Studies on lectins. XLVII. Some properties of D-galactose binding lectins isolated from the seeds of Butea frondosa, Erythrina indica and Momordica charantia. Biochim Biophys Acta 1980; 623(2): 439-48. [http://dx.doi.org/10.1016/0005-2795(80)90273-1] [PMID: 7397226]

[81] Aragon-Ortiz F, Nanne-Echandi CI, Fink E. Properties and N-terminal amino acid sequences of three Erythrina lectins from Costa Rica (Leguminosae). Rev Biol Trop 1994; 42(3): 467-71.

(C) 2017 Osman and Konozy.

This is an open access article distributed under the terms of the Creative Commons Attribution 4.0 International Public License (CC-BY 4.0), a copy of which is available at: (https://creativecommons.org/licenses/by/4.0/legalcode). This license permits unrestricted use, distribution, and reproduction in any medium, provided the original author and source are credited. 